\title{
Factors associated with malaria vaccine uptake in Sunyani Municipality, Ghana
}

\author{
Dennis Tabiri* ${ }^{*}$, Jean Claude Romaric Pingdwindé Ouédraogo and Priscilla Awo Nortey
}

\begin{abstract}
Background: Malaria continues to be a major disease of public health concern affecting several million people worldwide. The World Health Organization (WHO) started a pilot study on a malaria vaccine (RTS,S) in Ghana and two other countries in 2019. This study aimed at assessing the factors associated with uptake of the vaccine in the Sunyani Municipality of Ghana.

Methods: The study was a cross-sectional study employing a quantitative approach. Stratified sampling technique was used to select respondents. A structured questionnaire was administered to parents/caregivers with children eligible to have taken the first three doses of the malaria vaccine by December 2019. The Child Welfare Clinic (CWC) cards of the eligible children were also inspected. Ordinal logistic regression analysis was done to determine the association between the independent variables and full vaccine uptake.

Results: Uptake of RTS,S 1 was 94.1\%. However, this figure reduced to $90.6 \%$ for RTS,S 2, and 78.1\% for RTS,S 3. Children with a parent who had been educated up to the tertiary level had 4.72 (AOR: 4.72, 95\% Cl 1.27-17.55) increased odds of full uptake as compared to those who completed secondary education. Parents whose children had experienced fever as an adverse reaction were more likely to send their children for the malaria vaccine as compared to those whose children had ever suffered abscess as an adverse reaction (AOR: 2.27, 95\% Cl 1.13-5.10). Children with parents who thought vaccines were becoming too many for children had $71 \%$ (AOR: $0.29,95 \% \mathrm{Cl} 0.14-0.61$ ) reduced odds of full uptake as compared to those who thought otherwise.
\end{abstract}

Conclusion: Uptake of RTS,S 1 and RTS,S 2 in Sunyani Municipality meets the WHO's target coverage for vaccines, however, RTS,S 3 uptake does not. Furthermore, there is a growing perception amongst parents/caregivers that vaccines are becoming too many for children which negatively affects uptake.

Keywords: Malaria, Vaccine, Uptake

\section{Background}

Malaria continues to be a major disease of public health concern affecting several million people worldwide. According to the 2018 world malaria report, about 219 million malaria cases occurred worldwide in 2017. The report further indicates that sub-Saharan Africa represents the region with the highest burden. Ghana, together with nine other African countries and India

*Correspondence: dennistbr@gmail.com

Department of Epidemiology and Disease Control, School of Public

Health, University of Ghana, Accra, Ghana contributes about $70 \%$ of the world's total malaria burden. Children under 5 years of age are the worst affected. In $2017,49 \%$ and $61 \%$ of malaria cases and deaths respectively occurred in this age group according to the same report [1].

In Ghana, 11 million suspected cases of malaria and 5.5 million cases of confirmed malaria were estimated to have occurred in 2018. Approximately $30 \%$ of these cases occurred in children under 5 [2]. Malaria is an entirely preventable disease [3]. Several interventions have been introduced over the years in a bid to control malaria. Despite the proven effectiveness of these malaria control 
interventions, uptake remains low in some parts of the world [1]. The latest intervention to be introduced is the malaria vaccine.

The malaria vaccine known as Mosquirix, RTS,S/AS01, or simply RTS,S is the first vaccine proven to offer partial protection against malaria [3]. The World Health Organization (WHO), however, recommends the use of the vaccine on a pilot basis to inform its broader use. Subsequently, the world body approved a phased introduction of the malaria vaccine in 2019. Ghana, Kenya, and Malawi are the countries involved in this pilot study, in a program called Malaria Vaccine Implementation Programme (MVIP). Selected areas within these countries have been enrolled unto the programme [4].

In Ghana, between 120,000 and 150,000 children in 33 selected districts/Municipalities are targeted to receive the vaccine each year. The vaccine is to be given in four doses at 6, 7, 9 and 24 months of age through the routine Expanded Programme on Immunization (EPI) system [5].

Administration of the first doses of the malaria vaccine in Ghana begun in May 2019. However, news of the introduction of the vaccine was met with viral videos and messages on social media of some persons calling on the public to reject the vaccine. There were claims that the vaccine was unsafe and that Ghanaians were deceptively being used for vaccine trials [6].

The malaria vaccine is envisaged to prevent four out of ten malaria cases and three out of ten malaria deaths [3]. Nonetheless, globally, an estimated 1.5 million children die as a result of missing out on life-saving vaccines yearly [7]. In 2014, 31\% out of the 216 districts in Ghana did not achieve the target coverage of $80 \%$ for the proxy vaccine (Penta 3 ), indicating that some children continue to miss out on life-saving vaccines in Ghana [8].

The expected impact of the malaria vaccine is not likely to be seen in Ghana if uptake of the vaccine is not optimum. This study, therefore, sought to assess the factors associated with malaria vaccine uptake in the Sunyani Municipality of Ghana so that uptake can be maximized.

\section{Methods}

\section{Study area}

Sunyani Municipality is one of the 27 administrative districts in the Bono region of Ghana. Its estimated population for 2019 was 151,378 . Sunyani is the Municipality's capital. It lies between Latitudes $70^{\circ} 20^{\prime} \mathrm{N}$ and $70^{\circ} 05^{\prime} \mathrm{N}$, and Longitudes $20^{\circ} 30^{\prime} \mathrm{W}$ and $20^{\circ} 10^{\prime} \mathrm{W}$. It shares boundaries with Sunyani West district to the north, Asutifi district to the south, Tano North district to the east, and Dormaa East district to the west. The Municipality has a total land area of 829.3 square kilometres. One-third of the total land area is not inhabited or cultivated which provides arable land for development [9].
The Municipal Health Directorate (MHD) is in charge of health administration in the district. There are 33 health facilities that provide care to inhabitants of the Municipality. The Municipality is zoned into 34 functional Community-based Health Planning and Service (CHPS) zones under six sub-Municipalities. The subMunicipalities are Abesim, Antwikrom, Newtown/ Baakoniaba, New Dormaa, Sunyani central, and Penkwase. The CHPS zones are demarcated areas for the delivery of health services [9].

Childhood vaccines are delivered at health facilities and outreach points within the Municipality. The outreach points serve to deliver vaccines at the doorsteps of beneficiaries so that physical access does not hinder uptake. The outreach points are organized under the various CHPS zones in the 6 sub-Municipalities. The Municipality is noted for being one of the best in terms of vaccine coverage in the country. It is one of the reasons why it was selected as one of the implementing districts under the MVIP [9].

\section{Study design and sampling}

The study was an analytical cross-sectional study employing a quantitative approach.

Structured questionnaire and an observation checklist were used to collect data on malaria vaccine uptake and related factors. The assessment was done at a point in time giving a snapshot of the situation. Data was collected from parents/caregivers in Sunyani Municipality about themselves and their children on factors related to malaria vaccine uptake.

Cochrane's formula was used in to calculate the sample size; $\mathrm{n}=\frac{Z^{2} P q}{d^{2}}$ where $\mathrm{n}=$ sample size; $\mathrm{Z}=$ standard normal variate for margin of error; $p=$ proportion of children who take RTS,S vaccine; $\mathrm{q}=1$ - $\mathrm{p}$; $\mathrm{d}=$ margin of error.

Since this study was on uptake of a new vaccine, an assumed proportion of uptake of $50 \%$ was employed; using a margin of error of $5 \%$ and a $10 \%$ adjustment for non-response, the calculated sample size was 424 .

Stratified sampling technique proportionate to size was used in selecting participants from the six sub-Municipalities which served as strata. There are differences in the characteristics of the sub-Municipalities. Employing stratified sampling technique ensured that all sub-Municipalities were represented in the sample. It also allowed comparison to be made across sub-Municipalities.

In determining the proportionate sample size for each sub-Municipality, the formula below was used:

$$
\mathrm{A}=\frac{y}{z}
$$


where A is the sampling fraction, ' $y$ ' is the sample size = 424 , and ' $z$ ' is the 2019 monthly target coverage for vaccines in Sunyani Municipality $=505$.

The sampling fraction was applied to the monthly target of each sub-Municipality to determine the sample size for each sub-Municipality as shown in Table 1.

Systematic sampling was then used to select respondents from each stratum. A sampling frame was constructed using the Child Welfare Clinic (CWC) registers at the various CHPS zones. The CWC registers contain the official records of each vaccinated child in a particular CHPS zone. The frame contained the names of children who were eligible to have taken the first 3 doses of the malaria vaccine by December 2019, for each subMunicipality. A sampling interval was determined for each sampling frame using the formula:

$$
\mathrm{K}=\frac{N}{n},
$$

where $\mathrm{K}=$ sampling interval, $\mathrm{N}=$ the number of children in the sampling frame, and $\mathrm{n}=$ sample size for the sub-Municipality. Simple random sampling was used to select the first sample by writing the names of the children from one to the sampling interval, folded and mixed up in a bowl. One piece of paper was selected and the name on the paper represented the first sample. Subsequent samples were drawn by adding the sampling interval to the number of the first drawn sample until all samples required for the sub-Municipality were drawn.

The parents/caregivers of the selected children were contacted and those who agreed to be part of the study were interviewed.

\section{Data collection}

Data was collected through the administration of questionnaires to respondents and observation of CWC cards. Parents/caregivers were contacted at CWCs or in their houses depending on where they were available

Table 1 Sample size determination by sub-Municipality (proportionate to size)

\begin{tabular}{lclc}
\hline Sub-Municipality & $\begin{array}{l}\text { Monthly } \\
\text { target }(\mathbf{x})\end{array}$ & Sample fraction $\times \mathbf{x}$ & Sample size \\
\hline Abesim & 80 & $\frac{424}{505} \times 80$ & 67 \\
Antwikrom & 53 & $\frac{424}{505} \times 53$ & 45 \\
New Dormaa & 122 & $\frac{424}{505} \times 122$ & 102 \\
Newtown/Baakoniaba & 93 & $\frac{424}{505} \times 93$ & 78 \\
Penkwase & 78 & $\frac{424}{505} \times 78$ & 65 \\
Sunyani central & 80 & $\frac{424}{505} \times 80$ & 66 \\
Total & 505 & & 424 \\
\hline
\end{tabular}

to respond to the questionnaire. Questions centred on socio-demographic factors and other independent variables known to affect vaccine uptake. The other independent variables assessed were: knowledge about malaria vaccine, previous experience with vaccines and vaccination, affordability, and accessibility of vaccines in Sunyani Municipality.

The observation checklist centred on the uptake of malaria vaccine. The CWC card of the children provided this information.

Each questionnaire administration and CWC card observation lasted about $20 \mathrm{~min}$.

To ensure voluntary participation in the study, informed consent was obtained from each parent/caregiver before data collection. None of the parents/caregivers contacted refused to participate in the study, indicating a 100\% response rate.

\section{Data analysis}

The data was cleaned and entered into Microsoft excel. Entries were double-checked for errors and corrections made. It was then imported to STATA version 15 and analysed. Frequencies and percentages were generated for sociodemographic characteristics such as age, occupation, marital status, religion, and sex. Median and ranges were generated for the continuous variables.

Uptake of the malaria vaccine was measured as levels: no uptake (no dose received), partial uptake (either first or second dose received), and full uptake (all first three doses received). Ordinal logistic regression analysis was done to determine the association between the independent variables and the level of malaria vaccine uptake. The regression was done first at the univariate level. Independent variables with significant $\mathrm{p}$ values at the univariate level were used in a multivariate analysis and the model with the best Akaike's Information Criterion (AIC) and Bayesian's Information Criterion (BIC) was selected. For all associations, significance level was set at $5 \%$.

\section{Results}

\section{Socio-demographic characteristics}

A total of 424 parents/caregivers and 424 children participated in the study They were drawn from the six subMunicipalities in the Sunyani Municipality. The study lasted approximately 10 months.

The median age of parents/caregivers was 29 years (27, 32 years). It ranged from 17 to 45 years. Majority of them (99.3\%) were parents with almost all being females (99.5\%). Most respondents (60.9\%) were married with the rest being either single or cohabiting. Up to $43.2 \%$ of respondents had up to secondary education, whiles up to $41.5 \%$ of their partners, mostly males had up to tertiary 
Table 2 Distribution of socio-demographic characteristics of study participants, Sunyani Municipal, 2020

\begin{tabular}{|c|c|c|}
\hline Characteristic $(n=424)$ & Frequency & Percentage (\%) \\
\hline \multicolumn{3}{|l|}{ Sub-Municipality } \\
\hline Abesim & 68 & 16.0 \\
\hline Antwikrom & 45 & 10.6 \\
\hline Newtown/Baakoniaba & 78 & 18.4 \\
\hline New Dormaa & 102 & 24.1 \\
\hline Sunyani central & 66 & 15.6 \\
\hline Penkwase & 65 & 15.3 \\
\hline \multicolumn{3}{|l|}{ Age (years) } \\
\hline $15-19$ & 11 & 2.6 \\
\hline $20-24$ & 46 & 10.9 \\
\hline $25-29$ & 171 & 40.3 \\
\hline $30-34$ & 151 & 35.6 \\
\hline 35 and above & 45 & 10.6 \\
\hline \multicolumn{3}{|l|}{ Parent or caregiver } \\
\hline Parent & 421 & 99.3 \\
\hline Caregiver & 3 & 0.7 \\
\hline \multicolumn{3}{|l|}{ Sex } \\
\hline Male & 2 & 0.5 \\
\hline Female & 422 & 99.5 \\
\hline \multicolumn{3}{|l|}{ Marital status } \\
\hline Single & 99 & 23.4 \\
\hline Married & 258 & 60.9 \\
\hline Cohabiting & 67 & 15.8 \\
\hline \multicolumn{3}{|l|}{ Number of children alive } \\
\hline $1-3$ & 378 & 89.2 \\
\hline More than 3 & 46 & 10.8 \\
\hline \multicolumn{3}{|l|}{ Educational status } \\
\hline No formal education & 28 & 6.6 \\
\hline Primary education & 141 & 33.3 \\
\hline Secondary education & 183 & 43.2 \\
\hline Tertiary education & 72 & 17.0 \\
\hline \multicolumn{3}{|l|}{ Educational status of partner } \\
\hline No formal education & 14 & 3.3 \\
\hline Primary education & 72 & 17.1 \\
\hline Secondary education & 161 & 38.2 \\
\hline Tertiary education & 175 & 41.5 \\
\hline \multicolumn{3}{|l|}{ Religion } \\
\hline Christianity & 318 & 75.0 \\
\hline Islam & 103 & 24.3 \\
\hline Traditionalist & 3 & 0.7 \\
\hline \multicolumn{3}{|l|}{ Occupation } \\
\hline Unemployed & 87 & 20.5 \\
\hline Self-employed & 234 & 55.2 \\
\hline Farming & 32 & 7.6 \\
\hline Civil servant & 71 & 16.8 \\
\hline \multicolumn{3}{|l|}{ Religion of partner $(n=421)$} \\
\hline Christianity & 317 & 75.3 \\
\hline Islam & 100 & 23.8 \\
\hline Traditionalist & 4 & 1 \\
\hline
\end{tabular}

Table 2 (continued)

\begin{tabular}{lcc}
\hline Characteristic $(\mathbf{n}=\mathbf{4 2 4})$ & Frequency & Percentage (\%) \\
\hline Occupation of partner & & \\
Unemployed & 11 & 2.6 \\
Self-employed & 220 & 52.3 \\
Farming & 40 & 9.5 \\
Civil servant & 150 & 35.6 \\
\hline
\end{tabular}

education. Most of the respondents were Christians (75\%). Up to $55.2 \%$ of respondents were self-employed, whiles $20.5 \%$ of respondents were unemployed. However, only $2.6 \%$ of their partners were unemployed.

Details of the distribution of the socio-demographic characteristics of respondents are shown in the Table 2.

\section{Characteristics of children studied, Sunyani Municipality, 2020}

Out of the 424 children, $66.3 \%$ were aged $15-16$ months. Their ages ranged from 13 to 18 months. The median age was 15 months $(15,16$ months). Up to $55.4 \%$ of them were males. Almost all of them were delivered at a health facility (94.6\%).

Details of the characteristics of children studied are shown in Table 3.

\section{Uptake of RTS,S}

While 94.1\% (95\% CI 91.4-96.0\%) of the children had been administered the first dose of the malaria vaccine, 90.6\% (95\% CI 87.4-93.0\%) had been administered both the first and the second dose with a reduced percentage of 78.1 (95\% CI 73.9-83.8\%) having been administered all the three doses.

The reasons given for receiving some but not all the doses of the vaccine were: "did not know when the next one was due" $-45.6 \%$, "was not around", $-23.5 \%$, and

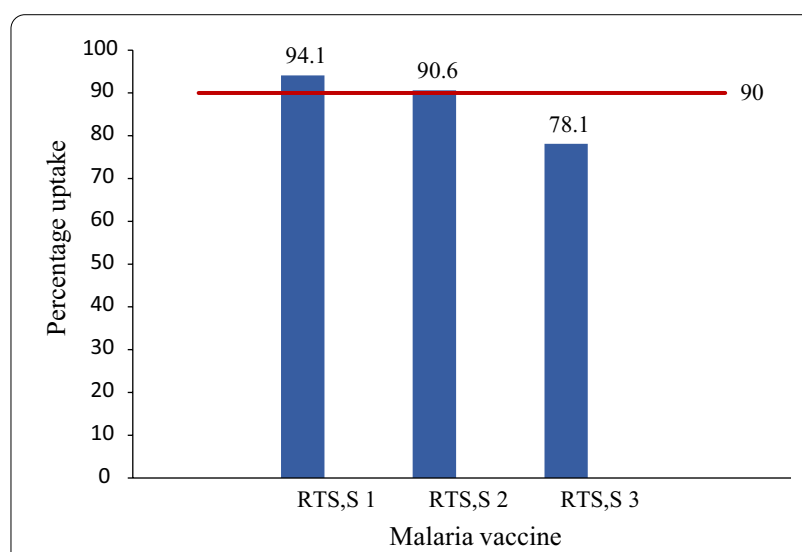

Fig. 1 Uptake of malaria vaccine in Sunyani Municipality. Blue bars: uptake (\%). Red bars: target 
Table 3 Distribution of characteristics of children studied, Sunyani Municipal, 2020

\begin{tabular}{lcc}
\hline Characteristic $(\mathbf{n}=\mathbf{4 2 4})$ & Frequency & Percentage (\%) \\
\hline Age (months) & 79 & 18.6 \\
$13-14$ & 281 & 66.3 \\
$15-16$ & 64 & 15.1 \\
$17-18$ & & \\
Sex & 235 & 55.4 \\
Male & 189 & 44.6 \\
Female & & \\
Place of delivery & 21 & 5.0 \\
Home & 401 & 94.6 \\
Health facility & 2 & 0.4 \\
Unknown & & \\
\hline
\end{tabular}

"not comfortable with issues surrounding vaccine" $-13.2 \%$. For those who had received no dose of the vaccine, $60 \%$ of the mothers said it was their partner's (husband) decision not to allow their children to be administered the vaccine whiles the rest said it was their own decision to refuse the vaccine.

Distribution of uptake of malaria vaccine in Sunyani Municipality is shown in Table 4.
Trend of uptake of malaria vaccine in Sunyani Municipality The uptake of malaria vaccine in Sunyani Municipality shows a declining uptake for the subsequent doses of the vaccine. Whiles uptake for the first dose was $94.1 \%$, it reduced to $90.6 \%$ for the second dose and to $78.1 \%$ for the third dose. RTS,S 1 and RTS,S 2 uptake met the WHO target of $90 \%$ but uptake of RTS,S 3 did not.

A chart of the uptake of the first three doses of malaria vaccine in Sunyani Municipality is shown in Fig. 1.

\section{Association between Independent variables and level of malaria vaccine uptake}

There was a significant association between the subMunicipality where one resided and level of uptake. Having a parent who had up to tertiary level education was associated with significantly increased odds of uptake. Details of association between independent variables and level of uptake is shown in Table 5.

\section{Multivariate analysis showing association between level of uptake and independent variables}

Multiple ordered logistic regression analysis using variables that were significant at $5 \%$ in the univariate

Table 4 Distribution of uptake of malaria vaccine in Sunyani Municipal, 2020

\begin{tabular}{|c|c|c|}
\hline Characteristic & Frequency & Percentage (\%) \\
\hline \multicolumn{3}{|l|}{ Level of uptake } \\
\hline No uptake & 25 & 5.9 \\
\hline Partial uptake & 68 & 16.0 \\
\hline Full uptake & 331 & 78.1 \\
\hline \multicolumn{3}{|l|}{ RTS,S 1 uptake } \\
\hline Yes & 399 & 94.1 \\
\hline No & 25 & 5.9 \\
\hline \multicolumn{3}{|l|}{ RTS,S 2 uptake } \\
\hline Yes & 384 & 90.6 \\
\hline No & 40 & 9.4 \\
\hline \multicolumn{3}{|l|}{ RTS,S 3 uptake } \\
\hline Yes & 331 & 78.1 \\
\hline No & 93 & 21.9 \\
\hline \multicolumn{3}{|l|}{ Reason for child receiving some but not all doses of RTS,S } \\
\hline Did not know when next one was due & 31 & 45.6 \\
\hline Was not around & 16 & 23.5 \\
\hline Not comfortable with side effects & 8 & 11.8 \\
\hline Not comfortable with issues surrounding vaccine & 9 & 13.2 \\
\hline Did not take previous one on time & 4 & 5.9 \\
\hline \multicolumn{3}{|l|}{ Reason for child receiving none of the doses of RTS,S } \\
\hline Partner's (husband) decision to refuse vaccine & 15 & 60.0 \\
\hline Personal decision to refuse vaccine & 7 & 28.0 \\
\hline Did not know child is eligible & 3 & 12 \\
\hline
\end{tabular}


analysis demonstrated that adjusted odds ratio for uptake per sub-Municipality was not significant.

As compared to secondary education, children with a parent who had been educated up to the tertiary level had an increased odds of 4.72 times of completing uptake. Children with parents/caregivers who thought vaccines were becoming too many for them with the addition of the malaria vaccine had $71 \%$ reduced odds of full uptake as compared to those who thought otherwise. This association was significant with a $p$ value of 0.001 .

Additionally, children who had suffered fever as an adverse reaction had an increased odds of 2.27 of their children completing uptake as compared to those whose children suffered abscess. Details of the multivariate analysis are depicted in Table 6.

\section{Discussion}

\section{Uptake of RTS,S}

Findings from this study indicated an uptake of 94.1\% for RTS,S 1; 90.6\% for RTS,S 2; and 78.1\% for RTS,S 3 . Uptake of RTS,S 1 and RTS,S 2 thus met the target of $90 \%$ coverage for vaccines set by WHO [10]. RTS,S 3 coverage, however, did not meet the set target.

There was a reduction in uptake of subsequent doses of the vaccine. This observed reduction is similar to that observed in Senegal, Cameroun, Nigeria, Togo, Congo, and in the Kwabre East district of Ghana [1116]. The over $90 \%$ uptake recorded for the RTS,S 1 and RTS,S 2 indicates that the anti-vaccine campaigns that greeted the introduction of the malaria vaccine did not impact negatively on the uptake of the vaccine in Sunyani Municipality [6]. This may have been so because the messages were largely on social media and did not really seep down to negatively influence parents/caregivers. It may also have been due to effective public education and other community mobilization strategies employed by the Municipality's health directorate to create awareness about the vaccine when it was introduced.

Out of the $5.9 \%$ of children who had not been administered any dose of the vaccine, most $(60 \%)$ were attributed to a partner's decision to refuse the vaccine (Table 4). Almost all the respondents were females indicating that it was the fathers who prevented their children from being administered the vaccine. Fathers play a major role in the family and are usually the decisionmakers. Those who prevented their children from being given the vaccine may have been influenced by the anti-vaccine campaigns. Fathers are usually not present at CWCs and so are not likely to benefit from education about vaccines which are usually delivered there.

It may also be the case that mothers were unwilling to admit during the interview that they themselves did not want their children to be vaccinated considering the fact that fathers were not around to respond.

The trend of reduced coverages for subsequent doses of the malaria vaccine may be due to poor knowledge of parent/caregivers about the schedule of the vaccines. This could result in parents/caregivers not presenting their children for the subsequent doses on time or not presenting them at all as was the case of $45.6 \%$ of respondents (Table 4). Up to $23.5 \%$ of children had not been administered all three doses because their parents/caregivers had travelled when they were due. This can be attributed to the fact that not all districts in the country are administering the vaccine (only districts on the MVIP). Therefore, when parents/caregivers travel to these non-implementing districts, their children may not be administered the vaccine at all or on time.

\section{Factors positively associated with uptake}

The findings of higher education and occupation being positive predictors of vaccine uptake are consistent with findings made by Adu, Ofosu, and Mukthar et al. [17-19]. Similarly, the findings of Acharya et al. [15] of higher education being associated with complete uptake was consistent with findings from this study.

Having a higher educated parent was associated with higher odds of complete uptake both in the univariate analysis and the multivariate analysis (AOR: 4.72, 95\% CI 1.27-17.55). This could be because highly educated parents have access to more information about the vaccine and were better placed to understand the implementation programme. Since most parents/caregivers who send their wards for vaccination services are women (99.5\%), having a partner who has higher education could mean that as the decision-maker, he is more likely to accept the vaccine. Having a higher education is associated with better occupation, the possible reason why civil servants had higher odds of their children completing uptake when compared.

Additionally, having a parent with primary education was also found to be associated with increased odds of full uptake in the multivariate analysis (AOR: 4.10, 95\% CI 1.02-16.47) as compared to having a parent with secondary education. This can be attributed to middle level educated parents being more susceptible to 
Table 5 Association between independent variables and level of uptake

\begin{tabular}{|c|c|c|c|}
\hline Characteristic & Odds ratio & 95\% confidence interval & P value \\
\hline Sub-Municipal & 0.79 & $0.69-0.92$ & 0.002 \\
\hline Penkwase (base) & 1 & & \\
\hline Abesim & 2.91 & $1.29-6.57$ & 0.010 \\
\hline Antwikrom & 5.36 & $1.71-16.79$ & 0.004 \\
\hline Newtown/Baakoniaba & 2.28 & $1.08-4.83$ & 0.031 \\
\hline New Dormaa & 1.41 & $0.73-2.73$ & 0.303 \\
\hline Sunyani central & 2.28 & $1.03-5.08$ & 0.043 \\
\hline Age of parent (years) & 1.06 & $0.82-1.37$ & 0.616 \\
\hline 20-24 (base) & 1 & & \\
\hline $15-19$ & 3.41 & $0.39-29.59$ & 0.266 \\
\hline $25-29$ & 1.03 & $0.48-2.20$ & 0.945 \\
\hline $30-34$ & 1.34 & $0.61-2.94$ & 0.463 \\
\hline 35 and above & 1.38 & $0.51-3.73$ & 0.522 \\
\hline Education level of parent/caregiver & 1.29 & $0.97-1.71$ & 0.075 \\
\hline Primary education (base) & 1 & 1 & \\
\hline No formal education & 1.52 & $0.54-4.30$ & 0.432 \\
\hline Secondary education & 1.36 & $0.82-2.26$ & 0.234 \\
\hline Tertiary education & 2.37 & $1.11-5.08$ & 0.026 \\
\hline Education level of partner & 1.02 & $0.78-1.35$ & 0.866 \\
\hline Secondary education (base) & 1 & 1 & \\
\hline No formal education & 2.56 & $0.55-11.89$ & 0.230 \\
\hline Primary education & 2.46 & $1.19-5.07$ & 0.015 \\
\hline Tertiary education & 2.08 & $1.25-3.45$ & 0.005 \\
\hline Number of children alive & 0.97 & $0.46-2.04$ & 0.940 \\
\hline 1-3 (base) & 1 & 1 & \\
\hline More than 3 & 0.97 & $0.46-2.04$ & 0.940 \\
\hline Marital status & 0.80 & $0.55-1.17$ & 0.254 \\
\hline Cohabiting (base) & 1 & 1 & \\
\hline Single & 1.60 & $0.78-3.27$ & 0.199 \\
\hline Married & 1.68 & $0.91-3.08$ & 0.097 \\
\hline Religion of parent/caregiver & 0.73 & $0.44-1.18$ & 0.205 \\
\hline Traditionalist (base) & 1 & 1 & \\
\hline Christian & 2.89 & $0.23-35.94$ & 0.409 \\
\hline Islam & 2.17 & $0.17-27.63$ & 0.551 \\
\hline Religion of partner & 0.73 & $0.45-1.19$ & 0.204 \\
\hline Traditionalist (base) & 1 & 1 & \\
\hline Christian & 1.68 & $0.16-17.29$ & 0.664 \\
\hline Islam & 1.21 & $0.12-12.85$ & 0.872 \\
\hline Occupation of parent/caregiver & 1.34 & $1.03-1.74$ & 0.027 \\
\hline Unemployed (base) & 1 & 1 & \\
\hline Self employed & 1.33 & $0.76-2.32$ & 0.319 \\
\hline Farmer & 2.66 & $0.85-8.39$ & 0.094 \\
\hline Civil servant & 2.21 & $1.00-4.90$ & 0.049 \\
\hline Occupation of partner & 1.13 & $0.89-1.43$ & 0.305 \\
\hline Self-employed (base) & 1 & 1 & \\
\hline Unemployed & 3.24 & $0.40-26.06$ & 0.268 \\
\hline Farmer & 3.07 & $1.05-9.01$ & 0.041 \\
\hline Civil servant & 1.365 & $0.84-2.23$ & 0.214 \\
\hline Known vaccine preventable diseases & 1.01 & $0.81-1.27$ & 0.899 \\
\hline Up to 3 vpds mentioned (base) & 1 & 1 & \\
\hline No correct vpd mentioned & 3.27 & $1.12-9.56$ & 0.031 \\
\hline $4-8$ correct vpds mentioned & 1.06 & $0.51-2.23$ & 0.870 \\
\hline Any correct disease but including malaria & 1.47 & $0.86-2.51$ & 0.164 \\
\hline
\end{tabular}


Table 5 (continued)

\begin{tabular}{|c|c|c|c|}
\hline Characteristic & Odds ratio & $95 \%$ confidence interval & $P$ value \\
\hline Heard about malaria vaccine & 0.64 & $0.30-1.36$ & 0.249 \\
\hline No (base) & 1 & 1 & \\
\hline Yes & 0.64 & $0.30-1.36$ & 0.249 \\
\hline Where first heard about malaria vaccine & 0.86 & $0.55-1.35$ & 0.510 \\
\hline Friends/relatives (base) & 1 & 1 & \\
\hline CWC & 20.22 & $1.61-253.71$ & 0.020 \\
\hline Health facility announcement & 16.78 & $1.18-239.11$ & 0.037 \\
\hline Radio & 39.68 & $2.14-737.14$ & 0.014 \\
\hline Number of times a child is expected to take the malaria vaccine & 1.26 & $0.67-2.34$ & 0.472 \\
\hline Incorrect number (base) & 1 & 1 & \\
\hline Correct number & 1.26 & $0.67-2.34$ & 0.472 \\
\hline Schedule of malaria vaccine & 1.26 & $0.55-3.04$ & 0.560 \\
\hline Incorrect order (base) & 1 & 1 & \\
\hline Correct order & 1.29 & $0.55-3.04$ & 0.560 \\
\hline Heard about any negative report or issue concerning the malaria vaccine & 1.72 & $1.03-2.88$ & 0.040 \\
\hline Yes (base) & 1 & 1 & \\
\hline No & 1.72 & $1.03-2.88$ & 0.040 \\
\hline Where issue or report was heard & 1.38 & $0.81-2.34$ & 0.232 \\
\hline Radio (base) & 1 & 1 & \\
\hline Friends/relatives & 2.75 & $1.37-5.51$ & 0.004 \\
\hline Health worker & 2.28 & $0.55-9.44$ & 0.255 \\
\hline Other & 1.08 & $0.85-13.60$ & 0.954 \\
\hline Did issue/report prevent or delay vaccine acceptance & 8.74 & $4.32-17.70$ & $<0.005$ \\
\hline Yes (base) & 1 & 1 & \\
\hline No & 8.74 & $4.32-17.70$ & $<0.005$ \\
\hline Given the option of accepting malaria vaccine at CWC & 1.15 & $0.69-1.93$ & 0.591 \\
\hline Yes (base) & 1 & 1 & \\
\hline No & 1.15 & $0.69-1.93$ & 0.591 \\
\hline Are vaccines becoming many for children with the introduction of the malaria vaccine & 0.60 & $0.38-0.97$ & 0.038 \\
\hline No (base) & 1 & 1 & \\
\hline Yes & 0.60 & $0.38-0.97$ & 0.038 \\
\hline \multicolumn{4}{|l|}{ Will you recommend malaria vaccine to others } \\
\hline No (base) & 1 & 1 & \\
\hline Yes & 12.61 & $7.00-22.72$ & $<0.005$ \\
\hline Child ever suffered an adverse reaction following the administration & 1.14 & $0.72-1.80$ & 0.576 \\
\hline No (base) & 1 & 1 & \\
\hline Yes & 1.14 & $0.72-1.80$ & 0.576 \\
\hline Reaction child suffered & 0.57 & $0.41-0.81$ & 0.001 \\
\hline Abscess (base) & 1 & 1 & \\
\hline Fever & 3.09 & $1.56-6.09$ & 0.001 \\
\hline Diarrhoea/vomiting & 5.56 & $0.67-46.00$ & 0.111 \\
\hline Did reaction influence acceptance of other vaccines & 1.87 & $0.56-6.27$ & 0.311 \\
\hline Yes (base) & 1 & 1 & \\
\hline No & 1.87 & $0.56-6.27$ & 0.311 \\
\hline Time taken to reach vaccination centre & 1.09 & $0.69-1.71$ & 0.724 \\
\hline Less than $30 \mathrm{~min}$ (base) & 1 & 1 & \\
\hline $30-59 \min$ & 1.06 & $0.65-1.74$ & 0.820 \\
\hline $1-2 \mathrm{~h}$ & 1.51 & $0.18-12.98$ & 0.706 \\
\hline Means of getting to vaccination centre & 1.23 & $0.77-1.99$ & 0.385 \\
\hline Walking (base) & 1 & 1 & \\
\hline Commercial vehicle & 1.43 & $0.85-2.40$ & 0.176 \\
\hline Personal vehicle & 0.411 & $0.07-2.47$ & 0.331 \\
\hline Required to pay any money at vaccination centre & 1.24 & $0.62-2.48$ & 0.544 \\
\hline
\end{tabular}


Table 5 (continued)

\begin{tabular}{|c|c|c|c|}
\hline Characteristic & Odds ratio & 95\% confidence interval & P value \\
\hline Yes (base) & 1 & 1 & \\
\hline No & 1.24 & $0.62-2.48$ & 0.544 \\
\hline How to tell when child's vaccination is due & 0.81 & $0.58-1.12$ & 0.195 \\
\hline Visit clinic monthly (base) & 1 & 1 & \\
\hline Check child'd CWC card & 1.57 & $0.97-2.54$ & 0.064 \\
\hline Told by nurses & 2.04 & $0.80-5.20$ & 0.136 \\
\hline Description of CWC nurses'attitude & 0.95 & $0.69-1.32$ & 0.779 \\
\hline Excellent (base) & 1 & 1 & \\
\hline Very good & 0.50 & $0.22-1.12$ & 0.092 \\
\hline Good & 0.61 & $0.27-1.40$ & 0.242 \\
\hline Do you think vaccines have long term side effects & 1.01 & $0.33-3.13$ & 0.984 \\
\hline Yes (base) & 1 & 1 & \\
\hline No & 1.01 & $0.33-3.13$ & 0.984 \\
\hline
\end{tabular}

Table 6 Multivariate analysis of association between level of uptake and independent variables

\begin{tabular}{|c|c|c|c|c|c|c|}
\hline Characteristic & Crude Odds ratio & $\begin{array}{l}95 \% \text { Confidence } \\
\text { interval }\end{array}$ & P-value & $\begin{array}{l}\text { Adjusted } \\
\text { Odds ratio }\end{array}$ & $\begin{array}{l}95 \% \text { Confidence } \\
\text { interval }\end{array}$ & P-value \\
\hline Sub-Municipal & 0.80 & $0.69-0.92$ & 0.002 & 0.82 & $0.66-1.02$ & 0.076 \\
\hline Penkwase (base) & 1 & 1 & & & & \\
\hline Abesim & 2.91 & $1.29-6.57$ & 0.010 & 2.21 & $0.53-9.17$ & 0.276 \\
\hline Antwikrom & 5.36 & $1.71-16.79$ & 0.004 & 2.01 & $0.16-26.03$ & 0.593 \\
\hline Newtown/Baakoniaba & 2.28 & $1.08-4.83$ & 0.031 & 1.22 & $0.32-4.62$ & 0.770 \\
\hline New Dormaa & 1.41 & $0.73-2.73$ & 0.303 & 0.36 & $0.10-1.29$ & 0.117 \\
\hline Sunyani central & 2.28 & $1.03-5.08$ & 0.043 & 0.98 & $0.27-3.50$ & 0.971 \\
\hline Education level of partner & 1.02 & $0.78-1.35$ & 0.866 & 1.02 & $0.60-1.75$ & 0.936 \\
\hline Secondary education (base) & 1 & 1 & & & & \\
\hline No formal education & 2.56 & $0.55-11.89$ & 0.230 & 0.93 & $0.02-31.06$ & 0.970 \\
\hline Primary education & 2.46 & $1.19-5.07$ & 0.015 & 4.10 & $1.02-16.47$ & 0.047 \\
\hline Tertiary education & 2.08 & $1.25-3.45$ & 0.005 & 4.72 & $1.27-17.55$ & 0.020 \\
\hline Occupation of partner & 1.13 & $0.89-1.44$ & 0.305 & 1.27 & $0.84-1.92$ & 0.257 \\
\hline Self-employed (base) & 1 & 1 & & & & \\
\hline Unemployed & 3.24 & $0.40-26.06$ & 0.268 & 1.74 & $0.17-17.42$ & 0.637 \\
\hline Farmer & 3.07 & $1.05-9.01$ & 0.041 & 0.97 & $0.08-11.06$ & 0.980 \\
\hline Civil servant & 1.365 & $0.84-2.23$ & 0.214 & 0.61 & $0.16-2.31$ & 0.464 \\
\hline $\begin{array}{l}\text { Vaccines becoming many for children with } \\
\text { the introduction of the malaria vaccine }\end{array}$ & 0.60 & $0.38-0.97$ & 0.038 & 0.29 & $0.14-0.61$ & 0.004 \\
\hline No (base) & 1 & 1 & & & & \\
\hline Yes & 0.60 & $0.38-0.97$ & 0.038 & 0.29 & $0.14-0.61$ & 0.001 \\
\hline Experience with AEFI & 0.57 & $0.41-0.81$ & 0.001 & 0.58 & $0.41-0.83$ & 0.003 \\
\hline Abscess (base) & 1 & 1 & & & & \\
\hline Fever & 3.09 & $1.56-6.09$ & 0.001 & 2.27 & $1.13-5.10$ & 0.023 \\
\hline Diarrhoea/vomiting & 5.56 & $0.67-46.00$ & 0.111 & 6.95 & $0.69-69.77$ & 0.099 \\
\hline
\end{tabular}


misinformation as compared to lower level educated parents. Whiles lower educated parents may rely on official communication such as health education at child welfare clinics and public announcements, middle level educated parents are more likely to be influenced by the antivaccine campaigns which were mainly on social media platforms.

\section{Factors negatively associated with uptake}

The findings of parents/caregivers having the perception that vaccines are becoming too many for their children is unique to this study per available literature reviewed. Those who thought vaccines for children (32.3\%) are becoming many had lower odds of completing uptake (AOR: 0.29, 95\% CI 0.14-0.61). This could be that parents/caregivers do not see the benefits of the child being vaccinated overriding the potential adverse effect that could occur when the vaccine is given.

Additionally, parents/caregivers who have children who have ever had fever as an adverse reaction (148/223) following immunization had a higher odds of completing uptake as compared to those who had abscess as an adverse reaction (64/223) (AOR: 3.09, 95\% CI 1.56-6.09). This could be related to the fact that most parents/caregivers consider fever to be a minor immediate side effect of vaccines as compared to developing an abscess. They were therefore not likely to 'risk' going for a new vaccine the safety of which has been questioned.

\section{Conclusion}

Uptake for the first and second doses of the malaria vaccine (RTS,S 1) in the Sunyani Municipality meets WHO's 90\% target. However, uptake of the third dose does not.

Whiles having a higher educated parent is associated with uptake positively, there is a growing perception that vaccines are becoming too many for children and this has a negative impact on uptake.

The Sunyani Municipal Health Directorate and the Ghana Health Service should conduct sustained public education on the malaria vaccine in Sunyani Municipality to further improve upon uptake.

\section{Appendix}

See Tables 7, 8, 9, 10, 11,12

Table 7 Operational definition and scale of measurement for dependent variable

\begin{tabular}{llll}
\hline Variable & Operational definition & Scale of measurement & Source of data \\
\hline Uptake of malaria vaccine & $\begin{array}{c}\text { Number of doses of malaria vaccine a child has } \\
\text { received }\end{array}$ & Ordinal & Child's CWC card \\
& $\begin{array}{l}\text { Full uptake (child has received all 3 doses) } \\
\text { dose) }\end{array}$ & No uptake (child has not received any dose)
\end{tabular}


Table 8 Operational definition and scale of measurement for socio-demographic variables

\begin{tabular}{|c|c|c|c|}
\hline Variable & Operational definition & Scale of measurement & Source of data \\
\hline Age & Age in completed years & Ratio & Interview \\
\hline Sex & Being male or female & Nominal & Observation \\
\hline \multirow[t]{7}{*}{ Place of residence } & Sub-Municipality in Sunyani within which parent/caregiver stays & Nominal & Interview \\
\hline & & Abesim & \\
\hline & & Antwikrom & \\
\hline & & Sunyani central & \\
\hline & & Newtown/Baakoniaba & \\
\hline & & New Dormaa & \\
\hline & & Penkwase & \\
\hline \multirow[t]{4}{*}{ Marital status } & Legal status of relationship with partner & Nominal & Interview \\
\hline & & Married & \\
\hline & & Single & \\
\hline & & Cohabiting & \\
\hline \multirow[t]{5}{*}{ Religion } & Religious denomination & Nominal & Interview \\
\hline & & Christian & \\
\hline & & Muslim & \\
\hline & & Traditionalist & \\
\hline & & Other & \\
\hline \multirow[t]{5}{*}{ Religion of partner } & Religious denomination & Nominal & Interview \\
\hline & & Christian & \\
\hline & & Muslim & \\
\hline & & Traditionalist & \\
\hline & & Other & \\
\hline \multirow[t]{5}{*}{ Educational level } & Highest formal education level attained & Ordinal & Interview \\
\hline & & None & \\
\hline & & Primary & \\
\hline & & Secondary & \\
\hline & & Tertiary & \\
\hline \multirow[t]{5}{*}{ Educational level of partner } & Highest formal education level attained by partner & Ordinal & Interview \\
\hline & & None & \\
\hline & & Primary & \\
\hline & & Secondary & \\
\hline & & Tertiary & \\
\hline \multirow[t]{5}{*}{ Occupation } & What the individual does for a living (brings him/her regular income) & Nominal & Interview \\
\hline & & Unemployed & \\
\hline & & Self-employed & \\
\hline & & Farming & \\
\hline & & Civil servant & \\
\hline \multirow[t]{5}{*}{ Occupation of partner } & What the partner does for a living (brings him/her regular income) & Nominal & Interview \\
\hline & & Unemployed & \\
\hline & & Self-employed & \\
\hline & & Farming & \\
\hline & & Civil servant & \\
\hline Parity & Number of children alive & Ratio & Interview \\
\hline
\end{tabular}


Table 9 Operational definition and scale of measurement for other independent variables

\begin{tabular}{|c|c|c|c|}
\hline Variable & Operational definition & Scale of measurement & Source of data \\
\hline \multirow[t]{14}{*}{ Knowledge about RTS,S } & \multirow{3}{*}{$\begin{array}{l}\text { Whether parent/caregiver has ever heard about the } \\
\text { malaria vaccine }\end{array}$} & Binary & \multirow[t]{3}{*}{ Interview } \\
\hline & & Yes & \\
\hline & & No & \\
\hline & \multirow{5}{*}{$\begin{array}{l}\text { Where parent/caregiver first heard about malaria } \\
\text { vaccine }\end{array}$} & Nominal & \multirow[t]{5}{*}{ Interview } \\
\hline & & CWC & \\
\hline & & Health facility announcement & \\
\hline & & Radio & \\
\hline & & Friend/relative & \\
\hline & \multirow{3}{*}{$\begin{array}{l}\text { Knowledge of the number of times a child is supposed } \\
\text { to be administered malaria vaccine }\end{array}$} & Binary & \multirow[t]{3}{*}{ Interview } \\
\hline & & Correct number & \\
\hline & & Incorrect number & \\
\hline & \multirow{3}{*}{$\begin{array}{l}\text { Knowledge of schedule of malaria vaccine administra- } \\
\text { tion }\end{array}$} & Binary & \multirow[t]{3}{*}{ Interview } \\
\hline & & Correct order & \\
\hline & & Incorrect order & \\
\hline \multirow[t]{3}{*}{ Perception of vaccines becoming too many } & \multirow{3}{*}{$\begin{array}{l}\text { Parent/caregiver thinks vaccines are becoming too } \\
\text { many for children with the introduction of malaria } \\
\text { vaccine }\end{array}$} & Binary & \multirow[t]{3}{*}{ Interview } \\
\hline & & Yes & \\
\hline & & No & \\
\hline \multirow[t]{3}{*}{ Concern about vaccine safety } & \multirow{3}{*}{$\begin{array}{l}\text { Heard about any negative issue/report concerning } \\
\text { malaria vaccine }\end{array}$} & Binary & \multirow[t]{3}{*}{ Interview } \\
\hline & & Yes & \\
\hline & & No & \\
\hline \multirow[t]{3}{*}{ Previous experience with vaccines } & \multirow{3}{*}{$\begin{array}{l}\text { Whether child has ever suffered an adverse reaction } \\
\text { following the administration of a vaccine }\end{array}$} & Binary & \multirow[t]{3}{*}{ Interview } \\
\hline & & Yes & \\
\hline & & No & \\
\hline Accessibility & Minutes spent in reaching nearest CWC & Ratio & Interview \\
\hline Affordability & Payment for vaccination services & Ratio & Interview \\
\hline \multirow[t]{6}{*}{ Perception of quality of vaccination service } & \multirow[t]{6}{*}{ Description of CWC nurses' attitude } & Ordinal & \multirow[t]{6}{*}{ Interview } \\
\hline & & Excellent & \\
\hline & & Very good & \\
\hline & & Good & \\
\hline & & Bad & \\
\hline & & Very bad & \\
\hline ANC attendance & $\begin{array}{l}\text { Number of times mother attended ANC before deliv- } \\
\text { ery of this child }\end{array}$ & Ratio & Interview \\
\hline \multirow[t]{3}{*}{ Sex of child } & \multirow[t]{3}{*}{ Child being male or female } & Nominal & \multirow[t]{3}{*}{ Interview } \\
\hline & & Male & \\
\hline & & Female & \\
\hline \multirow[t]{3}{*}{ Place of delivery } & \multirow[t]{3}{*}{ Where child was delivered } & Nominal & \multirow[t]{3}{*}{ Interview } \\
\hline & & Home delivery & \\
\hline & & Health facility & \\
\hline Time of uptake & $\begin{array}{l}\text { Age (in months) at which child was administered any } \\
\text { dose of malaria vaccine }\end{array}$ & Ratio & Child's CWC card \\
\hline
\end{tabular}


Table 10 EPI schedule In Ghana (without RTS,S)

\begin{tabular}{lll}
\hline Age of administration & Vaccine(s) & Mode of administration \\
\hline At birth & BCG, OPV 0 & Intradermal, oral \\
6 weeks & Penta 1, PCV 1, OPV 1, Rota 1, & Intramuscular, oral \\
10 weeks & Penta 2, PCV 2, OPV2, Rota 2 & Intramuscular, oral \\
14 weeks & Penta 3, IPV, PCV 3, OPV 3 & Intramuscular, oral \\
6 months & Vitamin A & Oral \\
9 months & Measles-rubella (MR) 1, yellow fever & Sub-cutaneous \\
12 months & Vitamin A & Oral \\
18 months & MR 2, Meningococcal 'A', Vitamin A & Subcutaneous, intramuscular, oral \\
\hline
\end{tabular}

Source: GHS, 2019

Table 11 EPI schedule with RTS,S for areas on MVIP in Ghana

\begin{tabular}{lll}
\hline Age of administration & Vaccine & Mode of administration \\
\hline At birth & BCG, OPV 0 & Intradermal, oral \\
$\mathbf{6}$ weeks & Penta 1, PCV 1, OPV 1, Rota 1, & Intramuscular, oral \\
$\mathbf{1 0}$ weeks & Penta 2, PCV 2, OPV 2, Rota 2 & Intramuscular, oral \\
$\mathbf{1 4}$ weeks & Penta 3, IPV, PCV 3, OPV 3 & Intramuscular, oral \\
$\mathbf{6}$ months & Vitamin A, RTS, S 1 & Oral, intramuscular \\
$\mathbf{7}$ months & RTS,S 2 & Intramuscular \\
$\mathbf{9}$ months & Measles-rubella (MR) 1, yellow fever, RTS, S 3 & Subcutaneous, intramuscular \\
$\mathbf{1 2}$ months & Vitamin A & Oral \\
$\mathbf{1 8}$ months & MR 2, Meningococcal 'A', Vitamin A & Subcutaneous, intramuscular, Oral \\
$\mathbf{2 4}$ months & RTS,S 4 & Intramuscular
\end{tabular}

Source: GHS, 2019

Bolds indicate changes that have occurred in the EPI schedule of MVIP selected areas in Ghana as a result of the introduction of RTS,S 
Table 12 Frequency distribution of responses

\begin{tabular}{|c|c|c|}
\hline Characteristic & Frequency & Percentage (\%) \\
\hline \multicolumn{3}{|c|}{ Sub-Municipality of residence $(n=424)$} \\
\hline Abesim & 68 & 16.0 \\
\hline Antwikrom & 45 & 10.6 \\
\hline Newtown/Baakoniaba & 78 & 18.4 \\
\hline New Dormaa & 102 & 24.1 \\
\hline Sunyani central & 66 & 15.6 \\
\hline Penkwase & 65 & 15.3 \\
\hline \multicolumn{3}{|l|}{ Age (years; $n=424$ ) } \\
\hline $15-19$ & 11 & 2.6 \\
\hline $20-24$ & 46 & 10.9 \\
\hline $25-29$ & 171 & 40.3 \\
\hline $30-34$ & 151 & 35.6 \\
\hline 35 and above & 45 & 10.6 \\
\hline \multicolumn{3}{|c|}{ Parent or caregiver $(n=424)$} \\
\hline Parent & 421 & 99.3 \\
\hline Caregiver & 3 & 0.7 \\
\hline \multicolumn{3}{|l|}{$\operatorname{Sex}(n=424)$} \\
\hline Male & 2 & 0.5 \\
\hline Female & 422 & 99.5 \\
\hline \multicolumn{3}{|l|}{ Marital status $(n=424)$} \\
\hline Single & 99 & 23.4 \\
\hline Married & 258 & 60.9 \\
\hline Cohabiting & 67 & 15.8 \\
\hline \multicolumn{3}{|c|}{ Number of children alive $(n=424)$} \\
\hline $1-3$ & 378 & 89.2 \\
\hline More than 3 & 46 & 10.8 \\
\hline \multicolumn{3}{|c|}{ Educational status ( $n=424$ ) } \\
\hline No formal education & 28 & 6.6 \\
\hline Primary education & 141 & 33.3 \\
\hline Secondary education & 183 & 43.2 \\
\hline Tertiary education & 72 & 17.0 \\
\hline \multicolumn{3}{|c|}{ Educational status of partner $(n=424)$} \\
\hline No formal education & 14 & 3.3 \\
\hline Primary education & 72 & 17.1 \\
\hline Secondary education & 161 & 38.2 \\
\hline Tertiary education & 175 & 41.5 \\
\hline \multicolumn{3}{|l|}{ Religion $(n=424)$} \\
\hline Christianity & 318 & 75.0 \\
\hline Islam & 103 & 24.3 \\
\hline Traditionalist & 3 & 0.7 \\
\hline \multicolumn{3}{|l|}{ Occupation ( $n=424)$} \\
\hline Unemployed & 87 & 20.5 \\
\hline Self-employed & 234 & 55.2 \\
\hline Farming & 32 & 7.6 \\
\hline Civil servant & 71 & 16.8 \\
\hline \multicolumn{3}{|c|}{ Religion of partner $(n=421)$} \\
\hline Christianity & 317 & 75.3 \\
\hline Islam & 100 & 23.8 \\
\hline Traditionalist & 4 & 1 \\
\hline
\end{tabular}


Table 12 (continued)

\section{Characteristic}

Frequency

Percentage (\%)

Occupation of partner $(n=421)$

Unemployed

Self-employed

Farming

Civil servant

Age of child in months $(n=424)$

13-14

15-16

17-18

$\operatorname{Sex}(n=424)$

Male

Female

Place of delivery $(n=424)$

Home

Health facility

Unknown

Level of uptake of RTS,S $(n=424)$

No uptake

Partial uptake

Full uptake

RTS,S 1 uptake $(n=424)$

Yes

No

RTS,S 2 uptake $(n=424)$

Yes

No

RTS,S 3 uptake $(n=424)$

Yes

No

Reason for child receiving some but not all doses of RTS,S ( $n=68$ )

Did not know when next one was due

Did not take previous one on time

Not comfortable with side effects

Not comfortable with issues surrounding vaccine

Was not around

Reason for child receiving none of the doses of RTS,S ( $n=25$ )

Personal decision to refuse vaccine

Partner's (husband) decision to refuse vaccine

Did not know child is eligible

Known vaccine-preventable diseases $(n=424)$

No correct disease mentioned

Up to 3 correct diseases mentioned

4-8 correct diseases mentioned

Any correct disease mentioned but including malaria

Heard about malaria vaccine $(n=424)$

Yes

No

Where first heard about malaria vaccine $(n=369)$

CWC 
Table 12 (continued)

\section{Characteristic}

Frequency

Percentage (\%)

Health facility announcement

28

Radio

Friend/relative

Number of times a child is supposed to receive the malaria vaccine $(n=369)$

Correct number

Incorrect number

Age order of receiving vaccines $(n=369)$

Correct order

Incorrect order

Heard about any negative report or issue concerning the malaria vaccine $(n=369)$

Yes

No

Where negative issue or report was heard $(n=225)$

Radio

Friends/relatives

Health workers

Other

Negative issue/report heard $(n=225)$

Vaccine is not safe

Children are being used for experiment

Vaccine will affect children's development

Issue/report prevented or delayed vaccine acceptance $(n=225)$

Yes

No

Given the option of accepting malaria vaccine at CWC $(n=369)$

Yes

No

Vaccines becoming many for children with the introduction of the malaria vaccine $(n=424)$

Yes

No

Recommend malaria vaccine to others

Yes

No

Reason for recommending vaccine $(n=357)$

It is safe

It protects children against malaria

Reason for not recommending vaccine $(n=67)$

Vaccine does not make any difference

No specific reason

Too many issues surrounding vaccine

Do not have much information on the vaccine

Child ever suffered an adverse reaction following the administration $(n=424)$

Yes

No

Reaction child suffered $(n=223$ )

Fever

Diarrhoea/vomiting 
Table 12 (continued)

\begin{tabular}{|c|c|c|}
\hline Characteristic & Frequency & Percentage (\%) \\
\hline \multicolumn{3}{|c|}{ Did reaction influence acceptance of other vaccines $(n=223)$} \\
\hline Yes & 12 & 94.6 \\
\hline No & 211 & 5.4 \\
\hline \multicolumn{3}{|c|}{ Time taken to reach vaccination centre $(n=424)$} \\
\hline Less than $30 \mathrm{~min}$ & 285 & 67.2 \\
\hline $30-59 \min$ & 132 & 31.1 \\
\hline $1-2 h$ & 7 & 1.7 \\
\hline \multicolumn{3}{|c|}{ Means of getting to vaccination centre $(n=424)$} \\
\hline Walking & 288 & 67.9 \\
\hline Commercial vehicle & 131 & 30.9 \\
\hline Personal vehicle & 5 & 1.2 \\
\hline \multicolumn{3}{|c|}{ Required to pay any money at vaccination centre $(n=424)$} \\
\hline Yes & 50 & 11.8 \\
\hline No & 374 & 88.2 \\
\hline \multicolumn{3}{|c|}{ How to tell when child's vaccination is due $(n=424)$} \\
\hline Ask friends & 12 & 2.8 \\
\hline Check child's CWC card & 218 & 51.4 \\
\hline Visit clinic monthly & 158 & 37.3 \\
\hline Told by nurses & 36 & 8.5 \\
\hline \multicolumn{3}{|c|}{ Description of CWC nurses' attitude $(n=424)$} \\
\hline Excellent & 54 & 12.7 \\
\hline Very good & 191 & 45.1 \\
\hline Good & 175 & 41.3 \\
\hline Bad & 4 & 0.9 \\
\hline \multicolumn{3}{|c|}{ Vaccines have long term side effects $(n=424)$} \\
\hline Yes & 17 & 4.0 \\
\hline No & 407 & 96.0 \\
\hline
\end{tabular}

\section{Abbreviations}

AEFI: Adverse Event Following Immunization; ANC: Ante-Natal Care; AOR Adjusted odds ratio; CWC: Child Welfare Clinic; CHPS: Community-based Health and Planning Service; EPI: Expanded Programme on Immunization; GHS: Ghana Health Service; GVAP: Global Vaccine Action Plan; MHD: Municipal Health Directorate; MVIP: Malaria Vaccine Implementation Program; RTS,S: Malaria vaccine.

\section{Acknowledgements}

Our appreciation goes to all respondents, lecturers of University of Ghana's School of Public Health and the WHO/TDR project team in Ghana.

\section{Authors' contributions}

DT and PAN made substantial contributions to the conception, design, acquisition of data, interpretation of data, drafting the manuscript and the critical review of the draft article. JCRPO made substantial contribution to the analysis of the study. All authors read and approved the final manuscript.

\section{Funding}

The study was Funded by the World Health Organization's special programme for Research and Training in Tropical Diseases (WHO/TDR), under the WHO/

TDR scholarship of the University of Ghana. The funding body played no role in the design of the study, collection, analysis, interpretation of data, and in writing the manuscript.

\section{Availability of data and materials}

The datasets used and/or analysed during the current study are available from the corresponding on reasonable request.

\section{Declarations}

Ethics approval and consent to participate

The study was approved by the Ghana Health Service Ethics Review Committee with approval number GHS-ERC029/12/19. All participants consented to participate in the study.

\section{Consent for publication}

Not applicable.

\section{Competing interests}

The authors declare that they have no competing interests.

Received: 13 April 2021 Accepted: 16 July 2021

Published online: 27 July 2021

\section{References}

1. WHO. World malaria report 2018. Geneva, World Health Organization, 2018. www.who.int/malaria. Accessed 23 Sep 2019.

2. District Health Information System. Malaria. 2019. https://dhims.chimgh. org/dhims/dhis-web-pivot/index.html. Accessed 3 Sep 2019.

3. WHO. Malaria. Geneva, World Health Organization, 2019. https://www. who.int/news-room/fact-sheets/detail/malaria. Accessed 12 Nov 2019.

4. Program for Appropriate Technology in Health. The RTS,S malaria vaccine. Seattle: PATH: 2019. 
5. Ghana Health Service. Ghana starts malaria vaccine implementation. 2019. http://www.ghana.gov.gh/index.php/media-center/news/5513 ghana-starts-malaria-vaccine-implementation. Accessed 20 Oct 2019.

6. Myjoyonline. Antimalaria vaccine: children not being used as guinea pigs. 2019. https://www.myjoyonline.com/lifestyle/2019/may-16th/antim alaria-vaccine-children-not-being-used-as-guinea-pigs-ghana-healthservice.php. Accessed 20 Oct 2019

7. WHO. Ten years in public health, 2007-2017: report by Dr. Margaret Chan, Director-General. Geneva, World Health Organization. 2017; p. 81-3. www.who.int/malaria. 7 Nov 2019.

8. Yawson AE, Bonsu G, Senaya LK, Yawson AO, Eleeza JB, Awoonor-Williams JK, et al. Regional disparities in immunization services in Ghana through a bottleneck analysis approach: implications for sustaining national gains in immunization. Arch Public Health. 2017;75:10.

9. Sunyani Municipal Health Directorate. Annual report, 2018. Sunyani: Sunyani Municipal Health Directorate; 2019.

10. WHO. Global Vaccine Action Plan: decade of vaccine collaboration. Vaccine. 2013;31:5-31.

11. Abdou M, Mbengue S, Sarr M, Faye A, Badiane O, Bintou F, et al. Determinants of complete immunization among Senegalese children aged 12-23 months : evidence from the demographic and health survey. BMC Public Health. 2017;17:630.

12. Russo G, Miglietta A, Pezzotti P, Biguioh RM, Mayaka GB, Sobze MS, et al. Vaccine coverage and determinants of incomplete vaccination in children aged 12-23 months in Dschang, West Region, Cameroon : a crosssectional survey during a polio outbreak. BMC Public Health. 2015;15:630

13. Adedire EB, Ajayi I, Fawole Ol, Ajumobi O, Kasasa S, Wasswa P, et al. Immunisation coverage and its determinants among children aged 12-23 months in Atakumosa-west district, Osun State Nigeria: a cross-sectional study. BMC Public Health. 2016;16:905.

14. Ekouevi DK, Gbeasor-komlanvi FA, Yaya I, Zida-compaore WI, Boko A, Sewu E, et al. Incomplete immunization among children aged 12-23 months in Togo: a multilevel analysis of individual and contextual factors. BMC Public Health. 2018;18:952.

15. Acharya P, Kismul H, Mapatano MA, Hatl A. Individual- and communitylevel determinants of child immunization in the Democratic Republic of Congo : a multilevel analysis. PLOS ONE. 2018;13:e0202742.

16. Wemakor A, Helegbe GK, Abdul-mumin A, Amedoe S, Zoku JA, Dufie Al. Prevalence and factors associated with incomplete immunization of children (12-23 months) in Kwabre East District, Ashanti Region, Ghana. Arch Public Health. 2018;76:9

17. Adu GA. Determinants of complete vaccination among children 24-35 months in Ga East Municipality of Accra. University of Ghana; 2017. http://ugspace.ug.edu.gh. Accessed 18 Oct 2019.

18. Ofosu SK. Factors contributing to immunization coverage in Assin North Municipality. University of Ghana; 2017. http://ugspace.ug.edu.gh. Accessed 18 Oct 2019.

19. Mukthar VK, Kulei SJ, Chege M. Determinants of pneumococcal conjugate vaccine uptake among children attending immunisation services at Kenyatta national hospital, Nairobi. Kenya East Afr Med J. 2015;92:348-53.

\section{Publisher's Note}

Springer Nature remains neutral with regard to jurisdictional claims in published maps and institutional affiliations.
Ready to submit your research? Choose BMC and benefit from:

- fast, convenient online submission

- thorough peer review by experienced researchers in your field

- rapid publication on acceptance

- support for research data, including large and complex data types

- gold Open Access which fosters wider collaboration and increased citations

- maximum visibility for your research: over $100 \mathrm{M}$ website views per year

At BMC, research is always in progress.

Learn more biomedcentral.com/submissions 